\title{
Web-Based Virtual Laboratory Development for Basic Practicums in Science and Technology
}

\author{
Sriadhi Sriadhi ${ }^{1}$, Abdul Hamid ${ }^{2}$, Restu Restu ${ }^{3}$ \\ ${ }^{1}$ Department of ITC Education, Universitas Negeri Medan, Medan, Indonesia, \\ ${ }^{2}$ Department of BT Education, Universitas Negeri Medan, Medan, Indonesia, \\ ${ }^{3}$ Postgraduate Program, Universitas Negeri Medan, Medan, Indonesia
}

\begin{abstract}
The limitations of laboratory practice lead to graduates' low competence. This study aims to develop a web-based virtual laboratory application to overcome the inability to implement laboratory practicums due to limited facilities and regulations related to the COVID-19 pandemic. The application was built using the system development life cycle (SDLC) model. The results from the LMS virtual labs test revealed the high suitability of the application for use. The Virtual Labs module application as LMS content was considered feasible and effective for use in basic science and technology laboratory practicums. The study recommended the use of the virtual laboratory application so that students could perform laboratory practicums virtually and independently as if in a real laboratory without being hindered by time, laboratory facilities, and instructors.
\end{abstract}

Keywords - Virtual Labs, science and technology, learning outcomes.

\section{Introduction}

The development of science and technology requires universities to prepare graduates according to the

DOI: $10.18421 /$ TEM111-50

https://doi.org/10.18421/TEM111-50

Corresponding author: Sriadhi Sriadhi,

Department of ITC Education, Universitas Negeri Medan, Medan, Indonesia.

Email: sriadhi@unimed.ac.id

Received: 03 January 2022.

Revised: 12 February 2022.

Accepted: 18 February 2022.

Published: 28 February 2022.

(cc)BY-Nc-ND (C) 2022 Sriadhi Sriadhi, Abdul Hamid \& Restu Restu; published by UIKTEN. This work is licensed under the Creative Commons Attribution-NonCommercialNoDerivs 4.0 License.

The article is published with Open Access at https://www.temjournal.com/ development of science, technology and stakeholder demands. Students in the fields of science and technology need sufficient laboratory practicums to be competent in their scientific field. To achieve this, there are many determining factors, such as teaching materials, learning facilities, and the learning process [1]. In the fields of science and technology, laboratory practicums are needed to provide professional competence [2]. In fact, it was discovered that student laboratory practicums were not always conducted due to a lack of facilities, a limited number of instructors, and the ratio of participants to the availability of practicum sessions [3]. This weakness has caused students' competence and learning outcomes to decrease.

Universitas Negeri Medan (Medan State University) has long been experiencing problems in the implementation of laboratory practicums, especially in the Faculty of Engineering. Under normal conditions, laboratory practicums are always delayed due to a lack of facilities, a substantial number of students using the laboratory, and limited availability of practicum sessions [4]. The existence of the COVID-19 pandemic has worsened the conditions because actual laboratory practicums were not allowed. Thus, innovative efforts are needed to overcome these problems.

The main problem relates to the low competence of students, especially students majoring in the fields of science and engineering. This problem is caused by the lack of laboratory practicums, which has led to students' competence and professional expertise learning outcomes decreasing. Innovative efforts are necessary to solve this problem so that the quality of education does not decrease further. These efforts include addressing the availability of practicum sessions, materials and equipment used, practicum mechanisms, and evaluation of laboratory practicum results. 


\subsection{The Purpose and Urgency of the Study}

This study aimed to build a virtual laboratory application system (Virtual Labs) that can be used by students to conduct basic laboratory practicums virtually. The practicums are devoted to students majoring in the fields of science and technology including the subjects of basic physics, basic electronics and basic electrical engineering. This application was developed to be web-based so that it could be accessed online and in real time. The stages of the research were as follows:

1) Analyze users' needs based on the curriculum and developments in science and technology.

2) Design a workflow that regulates the correlation between variables in the system.

3) Build a web-based e-learning LMS by establishing online learning activity features, teaching material storage, discussion forums, virtual practicum applications, and evaluations.

4) Test the performance of the web-based elearning LMS according to standards.

5) Develop Virtual Labs application modules covering basic concepts, multimedia animations, interactive simulations, worksheets, and virtual laboratory practicum simulations.

6) Test the feasibility of the Virtual Labs application module system based on the feasibility standard.

7) Test the effectiveness of the system as a virtual laboratory.

The results of this study were unique and novel. The proposal is an innovation in virtual laboratory practicum learning that visualizes abstract science events and makes them real, making them easily understood by students. In addition, the virtual laboratory was intended to solve problems that the laboratory practicums could not be conducted due to various limitations. Therefore, laboratory practicums needed to be performed virtually.

\subsection{Theoretical Study}

A virtual laboratory (Virtual Lab) is a laboratory consisting of interactive multimedia-based computer software designed to simulate laboratory activities as if the user was in an actual laboratory [5], [6]. Virtual laboratories utilize computer equipment and applications based on e-learning rules and the use of various media, such as videos, educational games, animations and simulations, to visualize laboratory activities as they are performed in actual laboratories [7], [8], [9]. The various advantages of a virtual laboratory practicum include visualization or simulation and interaction of experimental phenomena as if they occurred in an actual laboratory.
Laboratory practicums cannot be performed for several reasons, such as being of high risk and dangerous and limited facilities and resources [10], [11]. The existence of the COVID-19 pandemic has made virtual laboratories an absolute must for practicum learning because laboratory practicums are not allowed. A virtual laboratory enables students to perform practical work using computer-aided simulation applications combined with web-based resources; interactive media, educational videos, animations, and simulations and educational games in online learning environments [9].

Utilization of the Virtual Labs application makes learning more interesting, interactive, effective, and efficient; and learning can occur anywhere and anytime and in real time [12]. Virtual Labs simplifies complex processes into simple processes, visualizes abstract objects into reality, and reduces the risk of harm in science and technology periments [4], [11]. In addition, virtual laboratories with interactive simulations can improve creative thinking and problem solving skills, increase the meaning of what is learned, and provide a real context for learning with real conditions [13], [14].

The selection of Virtual Labs as a solution to this problem is based on the results of needs analysis and a literature review providing research results and previous best practices. Many studies have proven that virtual laboratories are effective for practical learning in various subjects such as physics [5]; [15], chemistry [10], biology [16], magnetism [17], basic electronics [7], computers [18], engineering education [14], [19]. The results of these studies have proven that virtual laboratories have many advantages, so it is considered appropriate to solve the problem of the absence of laboratory practicums that resulted in students' low learning outcomes.

\section{Research Methods}

This research was conducted at the State University of Medan - Indonesia in 2021 with the aim of developing basic laboratory practicums in the fields of science and technology. The application program was developed using the system development life cycle (SDLC) method through several stages, including (1) system investigation, (2) system analysis, (3) system design, and (4) system implementation [20]. The SDLC model was selected because it uses a complete cycle to identify users' needs. The framework of the CodeIgniter software and Personal Home Page (PHP) were used based on the advantages of their security systems, practicality and access speed. The database uses MySQL and PostgreSQL due to their advantages and the flexibility of the table structures [21]. 
LMS Virtual Labs performance testing refers to a life cycle procedure, namely, verifying that the program meets system requirements through stub testing, unit testing, black-box testing, white-box testing and integration testing [20]. The feasibility test of the Virtual Labs application module includes 9 aspects of the test, namely, the subject matter, auxiliary information, affective considerations, interface, navigation, pedagogy, invisible features, robustness, and supplementary material [22]. The effectiveness of the virtual laboratory system (webbased LMS \& Virtual Labs application module) was tested with the implementation of basic physics, basic electronics, and basic electrical engineering practicums.

\section{Results and Discussion}

Virtual Labs was developed in the form of a webbased learning LMS using the SDLC model. The investigation stage of the system succeeded in identifying the problems and system procedures; compiling alternative solutions; and classifying the system development, technical feasibility and economic feasibility. System analysis succeeded in classifying the data and system requirements and designing a new system that is more effective and efficient, easy (user-friendly) and logical. System design includes the conversion procedures for more detailed system services, compiling data structures, information display criteria, and system configuration. In the implementation stage, the system includes improving the system design, testing and installing new program applications and system testing. The application system provides three access groups: (a) administrators, (b) lecturers or lab staff, and (c) students. The system flow is shown in Figure 1.

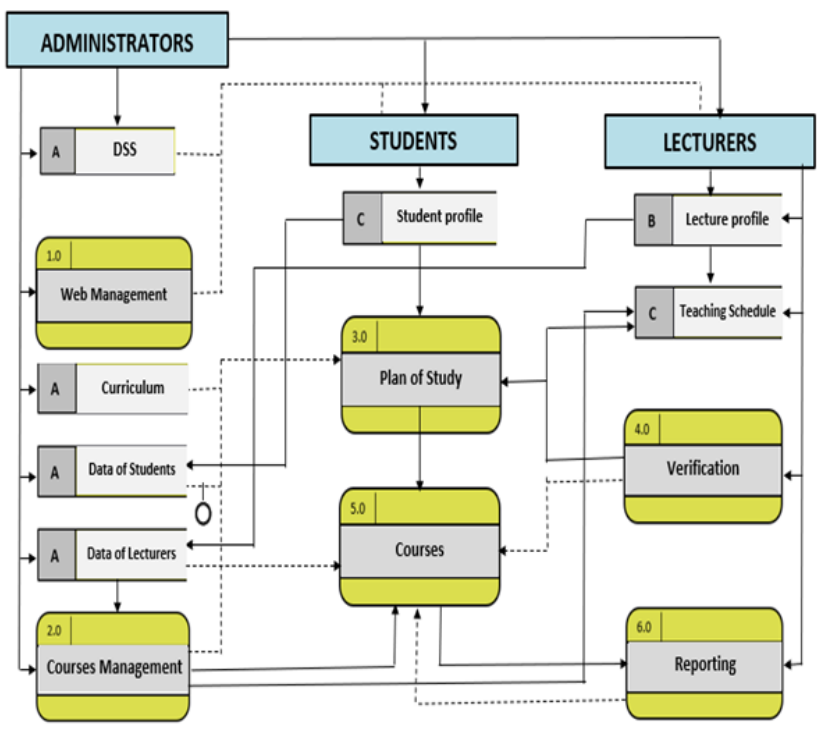

Figure 1. Data flow of the Virtual Labs system
A. An administrator logs in and has access to (1) academics to manage course data, lecture halls, study programs, faculties, and academic years; (2) students to manage active participants during lectures; (3) lecturers to manage caregivers and class schedules; and (4) lectures to manage lecturers' assignments, scheduling and student assessment management.

B. A lecturer logs in and has access to facilities including (1) approval of lecture participants; (2) lecture management that consists of lecture contracts, teaching materials and the storage of hyperlinks to YouTube, Google Drive, Dropbox and practicum assignments; and (3) assessment, including test instruments, exam schedules, and reports.

C. A student logs in and has access to (1) practicum registration; (2) downloaded teaching material documents, presentation slides, videos, animations, and virtual practicum simulations; and (3) examination and report results.

Figure 2. and Figure 3. show some of the features available in the Virtual Labs application program.

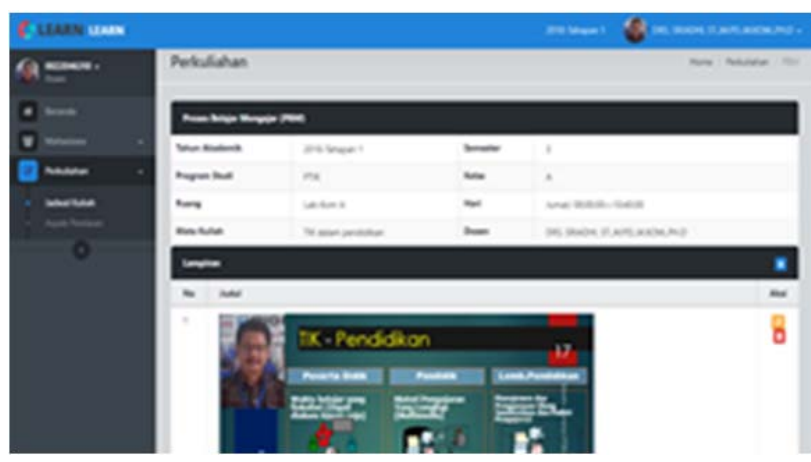

Figure 2. Display of the Virtual Labs LMS

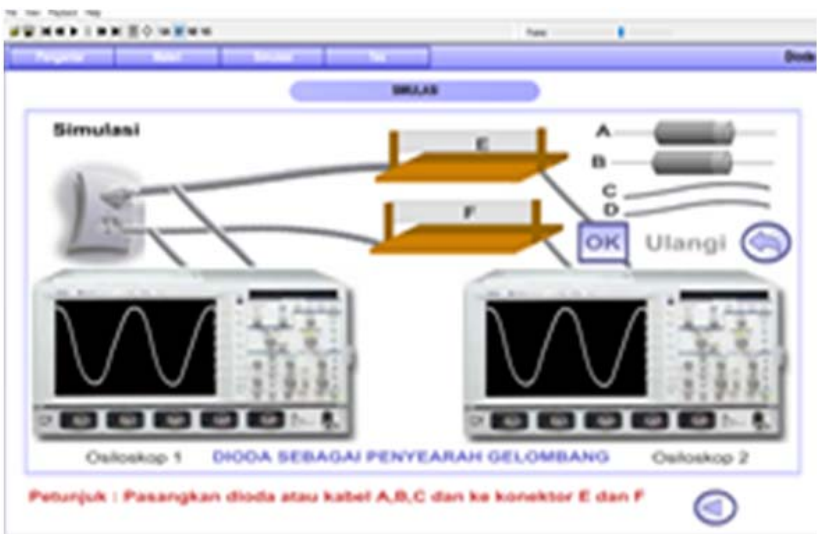

Figure 3. Virtual experiment of Dioda

Program performance testing using SDLC syntax was performed on each program model unit to test whether the performance was in accordance with the design, unit integration and connection reliability in the system. The final results of the test based on all aspects of the criteria group showed its feasibility, and the results are shown in Table 1. 
Table 1. Feasibility of LMS Virtual Labs

\begin{tabular}{|c|c|c|c|}
\hline No & Aspects \& Criteria & Feasibility & Average \\
\hline \multirow{10}{*}{1} & \multicolumn{2}{|c|}{ Design \& Construction } & \multirow[t]{10}{*}{87.30} \\
\hline & a. layout system & 83.67 & \\
\hline & b. program facilities & 88.00 & \\
\hline & c. navigation & 93.67 & \\
\hline & d. hyperlink & 95.00 & \\
\hline & e. interface & 82.67 & \\
\hline & f. interactivities & 85.67 & \\
\hline & g. visualization & 92.00 & \\
\hline & h. color resolution & 85.00 & \\
\hline & i. operational system & 80.00 & \\
\hline \multirow{4}{*}{2} & \multicolumn{2}{|c|}{ User needs } & \multirow[t]{4}{*}{81.89} \\
\hline & a. needs representative & 80.33 & \\
\hline & b. level of usage & 82.33 & \\
\hline & c. help desk system & 83.00 & \\
\hline \multirow{4}{*}{3} & \multicolumn{2}{|c|}{ Reliability } & \multirow[t]{4}{*}{86.56} \\
\hline & a. stability & 82.67 & \\
\hline & b. consistency & 89.00 & \\
\hline & c. compatibility & 88.00 & \\
\hline \multirow{4}{*}{4} & \multicolumn{2}{|c|}{ Security system } & \multirow[t]{4}{*}{84.67} \\
\hline & a. login system & 91.67 & \\
\hline & b. program security & 80.00 & \\
\hline & c. multiple layers & 82.33 & \\
\hline \multirow{5}{*}{5} & \multicolumn{2}{|l|}{ Ease of use } & \multirow[t]{4}{*}{83.33} \\
\hline & a. usability & 85.67 & \\
\hline & b. friendly & 81.00 & \\
\hline & c. support system & 83.33 & \\
\hline & \multicolumn{2}{|l|}{ Total mean } & 85.48 \\
\hline
\end{tabular}

Web-based LMS testing was executed several times to obtain eligibility according to the established standards. Design and construction obtained the highest score of $87.3 \%$, as required. Furthermore, the user needs aspect, although feasible, needs to be improved to meet user needs. The differences in students' initial abilities in mastering the three subjects caused differing needs that need to be followed up with more specific activities for these needs to be accommodated into Virtual Labs application content. The overall test results showed that all aspects of the LMS were confirmed to be feasible with results greater than $80 \%$.

After the web-based learning LMS system was confirmed to be feasible, the next test was the feasibility of the Virtual Labs module application as LMS content. Tests were performed by validators who were experts in the fields of educational technology, multimedia learning and teaching materials. Using the criteria from Alessi and Trollip (2001), the results of the feasibility test for the Virtual Labs module application are shown in Figure 4.

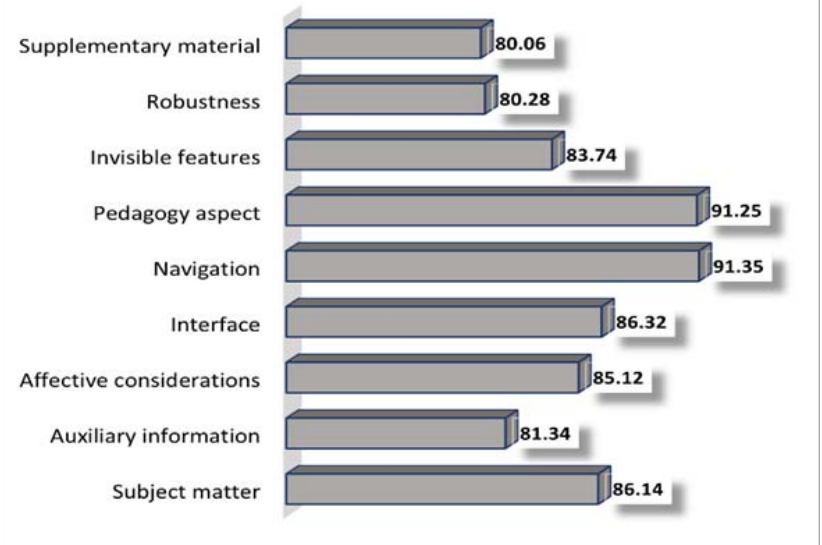

Figure 4. Feasibility of the Virtual Labs module

The tests for the virtual laboratory module were conducted several times according to the feasibility of each aspect. Some aspects, such as the pedagogy and navigation aspects, were found to be feasible with very high eligibility criteria in the first test. However, other aspects, namely, robustness and supplementary materials, were improved several times until they were found to be feasible. The eligibility limit for the Virtual Labs module was set at a minimum of $80 \%$ to ensure content validity, although in its implementation, lecturers would continue to develop the content on an ongoing basis as needed.

The next test was the test of effectiveness of the system through the implementation of lectures using the Virtual Labs system (web-based LMS \& Virtual Labs module application) for the basic physics, basic electronics and basic electrical engineering modules. The measurement used a scale of 5 for groups of students in three study programs, namely, informatics technology and computer education (ITCE), electrical engineering education (EEE), electrical engineering (EE); and the results are shown in Table 2 .

Table 2. Mean score of effectiveness

\begin{tabular}{|c|l|c|c|c|c|}
\hline No & \multicolumn{1}{|c|}{ Aspects } & ICTE & EEE & EE & Average \\
\hline 1 & Content relevance & 4.65 & 4.35 & 4.26 & 4.42 \\
\hline 2 & Teaching materials & 3.82 & 3.79 & 3.74 & 3.78 \\
\hline 3 & Concept clarity & 4.25 & 4.28 & 4.12 & 4.22 \\
\hline 4 & $\begin{array}{l}\text { Practical } \\
\text { application }\end{array}$ & 3.68 & 4.64 & 4.36 & 4.23 \\
\hline 5 & Simulation Media & 3.86 & 4.52 & 3.88 & 4.09 \\
\hline 6 & $\begin{array}{l}\text { Practical } \\
\text { Mechanism }\end{array}$ & 4.64 & 4.58 & 4.35 & 4.52 \\
\hline 7 & Data recording & 4.32 & 4.25 & 4.61 & 4.39 \\
\hline 8 & Enrichment & 3.64 & 3.42 & 3.28 & 3.45 \\
\hline 9 & $\begin{array}{l}\text { Level of } \\
\text { competences }\end{array}$ & 4.62 & 4.68 & 4.35 & 4.55 \\
\hline 10 & Acceptability & 4.53 & 4.55 & 4.42 & 4.50 \\
\hline 11 & Student motivation & 4.28 & 4.56 & 4.52 & 4.45 \\
\hline 12 & $\begin{array}{l}\text { Learning } \\
\text { satisfaction }\end{array}$ & 4.68 & 4.35 & 4.36 & 4.46 \\
\hline & \multicolumn{1}{|c|}{ Total } & 4.25 & 4.33 & 4.19 & 4.26 \\
\hline
\end{tabular}


The results of the data analysis showed that 10 of the 12 aspects obtained a mean score greater than 4.0 , which was categorized as very high. Learning outcomes (LO) achieved the highest average score of 4.55 , which was equivalent to $90.1 \%$. Some of the supporting aspects of the practicum materials developed in the application were very relevant, with an average score of $4.42(88.4 \%)$. The practicum mechanism achieved a score of $4.52(90.4 \%)$, and the availability of simulation media and data recording of practicum results was greater than $80 \%$. Support for these aspects was required by students to perform the practicum correctly and effectively. The results of this study agreed with those of previous relevant studies conducted by Dhang et al. [7], Gupta [11], and Shopi and Eka [15].

Animation and simulation media also played a very significant role in improving students' understanding in virtual laboratory practicums. This was a result of the process of preparing animation and simulation media on the Virtual Labs application module that paid attention to the principles of multimedia design, as emphasized by Mayer [23]. In addition, cognitive load reduction was also implemented to improve the information processing system so that information could be received, understood, and stored in the brain system, as emphasized by Clark and Mayer [24]. In the development of this virtual laboratory module, the role of artificial intelligence in the form of augmented reality and virtual reality was also very substantial so that it could meet the students' needs, especially to answer the problem related to the absence of real-time laboratory practicum due to various obstacles. The results of this study strengthened the findings of previous studies, especially the research conducted by Nantsou et al. [12].

Regarding acceptability, an average score of 4.5 was obtained, meaning that the acceptability of the Virtual Lab module application reached $90 \%$ according to users' (student) expectations. This acceptance increased students' learning motivation, which was classified as high (89\%) and ultimately led to $89.2 \%$ satisfaction with using the Virtual Labs application module. The improvement of these psychological aspects was necessary because it affected learning activities that would determine the achievement of the students' laboratory practicum learning outcomes, as evidenced in previous studies [8], [25]. There were two aspects that still need to be improved, namely, the scope of the content material and enrichment. However, the results of the overall effectiveness analysis of the Virtual Labs application module were high, with a total mean score of 4.26 equivalent to $83.2 \%$. Thus, the Virtual Labs application module proved to be feasible and effective for use as a virtual laboratory practicum model. The eligibility included web-based e-learning as an LMS that could be accessed online and the
Virtual Labs application module as LMS content to support virtual laboratory practicums with $90.1 \%$ effectiveness.

If analyzed based on the respondent group, the mean scores of the effectiveness of the three study programs had differences, even though the mean scores were still high. For this reason, comparative statistical analysis was executed using the ANOVA technique. The results of the test of the homogeneity of variances, which are the requirements of the analysis, obtained a $\mathrm{P}$ value of 0.765 . This means that the three groups were affirmed to be homogeneous at $=5 \%$. Then, a comparison test was conducted using one-way ANOVA, and the results are shown in Table 3.

Table 3. ANOVA

\begin{tabular}{|l|c|c|c|c|c|}
\hline \multicolumn{7}{|c|}{ Effect.Aspects } \\
\hline & $\begin{array}{c}\text { Sum of } \\
\text { Squares }\end{array}$ & df & $\begin{array}{c}\text { Mean } \\
\text { Square }\end{array}$ & F & Sig. \\
\hline Between Groups & .124 & 2 & .062 & .420 & .660 \\
\hline Within Groups & 4.884 & 33 & .148 & & \\
\hline \multicolumn{1}{|c|}{ Total } & 5.008 & 35 & & & \\
\hline
\end{tabular}

The ANOVA test results show a $\mathrm{P}$ value of 0.660 , which accepts Ho. These results proved that there were no significant differences in the effectiveness of using the Virtual Labs application module in the three sample groups. The effectiveness of using the Virtual Labs application in the informatics technology and computer education study program reached an average score of 4.25 , which means that the problem of low student competence due to the limitations of laboratory practicum can be solved with $85 \%$ effectiveness through virtual laboratory practicum using the Virtual Labs application. Likewise, the electrical engineering education and electrical engineering study programs reached effectivenesses of $86.6 \%$ and $83.8 \%$, respectively. The results of this study were in line with the research of Tatli and Ayas [10], which confirmed that virtual laboratories could solve the issues of basic chemistry practicums; Murniza's research [16], in biology through the VLab-Bio application; and Gupta's research [17], in the field of a virtual lab module for concepts of electric and magnetic fields. Thus, the results of this study proved that Virtual Labs could be a solution to the problem of the absence of basic laboratory practicum in the fields of science and technology due to limited facilities or other obstacles, such as the COVID-19 pandemic. Virtual laboratories are the right solution that strive to increase students' learning outcomes from virtual laboratory practicums without being limited by time, place, facilities, instructors, laboratory assistants and other limitations. 


\section{Conclusion}

Competence in the field of student expertise is determined by the laboratory practicum that has been conducted. The limitations of laboratory facilities and the COVID-19 pandemic have prevented laboratory practicums from being performed, which resulted in very low student competence. This research succeeded in developing a virtual laboratory practicum model. LMS web-based e-learning was considered feasible through a series of tests; and the Virtual Labs application module for laboratory practicums in the fields of basic physics, basic electronics, and basic electrical engineering as LMS content had also been found to achieve high effectiveness. Henceforth, virtual laboratory practicum modules for other fields need to be developed. The Virtual Labs application is an innovative method to solve the problem of the low competence of students' skills due to the absence of laboratory practicums. The development of the webbased Virtual Labs application as a result of this research can be a solution to these problems and can be used as a basis for the development in other fields as needed.

\section{Acknowledgments}

This paper is written based on the results of a study that has been conducted in accordance with contracts No. 190/SP2H/AMD/LT/DRPM/2020

and No.214/E4.1/AK.04.PT/2021.

The authors would like to thank the Government of the Republic of Indonesia and Medan State University for facilitating this research until its completion.

\section{References}

[1]. Bhatti, Z., Abro, A., Gillal, A. R., \& Karbasi, M. (2017). Be-Educated Multimedia Learning Through 3D Animation. International Journal of Computer Science and Emerging Technologies, 1(1), 13-22.

[2]. Kiat, T. Y., Jumintono, K., ES, S., Handayani, E., Anggarini, Y., \& Rofik, M. (2020). The effectiveness of multimedia learning on academic achievement in reproduction topic science subject. Universal Journal of Educational Research, 8(8), 3625-3629.

[3]. Sriadhi, S., Restu, R., \& Sitompul, H. (2021, March). Multimedia simulation model for electrical laboratory learning. In IOP Conference Series: Materials Science and Engineering (Vol. 1098, No. 3, p. 032020). IOP Publishing.

[4]. Sriadhi, S., Restu, R., Sitompul, H., \& Manurung, J. (2019, December). Development of web-virtual laboratory to improve the effectiveness and efficiency of remedial learning. In Journal of Physics: Conference Series (Vol. 1402, No. 7, p. 077059). IOP Publishing.
[5]. İnce, E., Kırbaşlar, F. G., Güneş, Z. Ö., Yaman, Y., Yolcu, Ö., \& Yolcu, E. (2015). An innovative approach in virtual laboratory education: The case of "IUVIRLAB" and relationships between communication skills with the usage of IUVIRLAB. Procedia-Social and Behavioral Sciences, 195, 1768-1777. https://doi.org/10.1016/j.sbspro.2015.06.377

[6]. Chiodi, G. A., Soutadet, A. J., \& Bosio, M. A. (2021). Virtual Laboratory and Mobile Devices as a Support Tool for the Teaching-Learning Processes of Physics in Pandemic Times. International Journal of Recent Contributions from Engineering, Science \& IT (IJES), 9(3), 76. https://doi.org/10.3991/ijes.v9i3.24473.

[7]. Dhang, S., \& Chittaranjan, M. (2017). Virtual laboratory for basic electronics. Journal of Engineering, Science and Management Education, 10(1), 67-74.

[8]. Gabajová, G., Furmannová, B., \& Rolinčinová, I. (2020). Use of augmented and virtual reality in industral engineering. Acta Tecnol, 6(2), 31-34.

[9]. Estriegana, R., Medina-Merodio, J. A., \& Barchino, R. (2019). Student acceptance of virtual laboratory and practical work: An extension of the technology acceptance model. Computers \& Education, 135, 114.

https://doi.org/10.1016/j.compedu.2019.02.010

[10]. Tatli, Z., \& Ayas, A. (2010). Virtual laboratory applications in chemistry education. Procedia-Social and behavioral sciences, 9, 938-942.

https://doi.org/10.1016/j.sbspro.2010.12.263

[11]. Potkonjak, V., Gardner, M., Callaghan, V., Mattila, P., Guetl, C., Petrović, V. M., \& Jovanović, K. (2016). Virtual laboratories for education in science, technology, and engineering: A review. Computers \& Education, 95, 309-327. https://doi.org/10.1016/i.compedu.2016.02.002.

[12]. Nantsou, T. P., Kapotis, E. C., \& Tombras, G. S. (2021). A Physics and Engineering Lab for Primary Teachers at CERN. International Journal of Recent Contributions from Engineering, Science \& IT (IJES), 9(3), 20. https://doi.org/10.3991/ijes.v9i3.24753.

[13]. Trnka, P., Vrána, S., \& Šulc, B. (2016). Comparison of various technologies used in a virtual laboratory. IFAC-PapersOnLine, 49(6), 144-149. https://doi.org/10.1016/j.ifacol.2016.07.168

[14]. Zotova, M., Likhouzova, T., Shegai, L., \& Korobeynikova, E. (2021). The Use of MOOCS in Online Engineering Education. International Journal of Engineering Pedagogy, 11(3), 157-173. https://doi.org/10.3991/IJEP.V11I3.20411

[15]. Maulidah, S. S., \& Prima, E. C. (2018). Using Physics Education Technology as Virtual Laboratory in Learning Waves and Sounds. Journal of Science Learning, 1(3), 116-121.

[16]. Muhamad, M., Zaman, H. B., \& Ahmad, A. (2012). Virtual biology laboratory (VLab-Bio): Scenariobased learning approach.Procedia-Social and Behavioral Sciences, 69, 162-168. https://doi.org/10.1016/j.sbspro.2012.11.395. 
[17]. Gupta, T., Prachi, S. M. A., Akhtar, J. M., \& Srivastava, V. K. (2012). Development of the virtual lab module for understanding the concepts of electric and magnetic field patterns in rectangular waveguides and cavities. International Journal of Online Engineering, 8(3), 12-21. https://doi.org/10.3991/ijoe.v8i3.2113.

[18]. Sus, B., Tmienova, N., Revenchuk, I., \& Vialkova, V. (2019, October). Development of virtual laboratory works for technical and computer sciences. In International Conference on Information and Software Technologies (pp. 383-394). Springer, Cham.

https://doi.org/10.1007/978-3-030-30275-7 29.

[19]. Giang, N. T. H., Hai, P. T. T., Tu, N. T. T., \& Tan, P. X. (2021). Exploring the readiness for digital transformation in a higher education institution towards industrial revolution 4.0. International Journal of Engineering Pedagogy, 11(2), 4-24. https://doi.org/10.3991/IJEP.V11I2.17515.
[20]. Whitten, J. L., Bentley, L. D. (2007). Systems Analysis and Design Methods (7th ed.). McGraw Hill Irwin.

[21]. Laudon, K. C., \& Laudon, J. P. (2015). Management information system. Pearson Education India.

[22]. Alessi, S. M., \& Trollip, S. R. (2001). Multimedia for learning: Methods and development. Allyn \& Bacon.

[23]. Mayer, R. E. (2014). Multimedia Learning (2nd ed.). Cambridge University press.

[24]. Clark, R., and Mayer, R. E. (2011). E-Learning and the science of instruction (2nd ed.). J. Wiley inc.

[25]. Bajpai, M., \& Kumar, A. (2015). Effect of virtual laboratory on students' conceptual achievement in physics. International Journal of Current Research, 7(2), 12808-12813. 